\title{
Expertis, sjukskrivning och mötet mellan normal och post-normal vetenskap
}

\author{
LENA ERIKSSON, MORTEN SAGER, \\ CARIN STALAND-NYMAN \& GUNNEL HENSING
}

Läkares erfarenheter av otillräcklighet vid sjukskrivning är ett uttryck för två problem: Formatet för det försäkringsmedicinska beslutsstödet begränsar vilka aspekter av sin expertkunskap läkare kan förmedla till Försäkringskassan, och man tvingas hantera ett kunskapsobjekt utanför sin etablerade expertis. Nuvarande strategier behandlar symtomen på ett kunskapsteoretiskt glapp, snarare än att höja expertisen kring arbetsförmåga.

\section{Inledning och syfte}

Konsekvenserna av de nya hårdare reglerna i sjukförsäkringen har diskuterats

Lena Eriksson, forskare, Institutionen för Filosofi, Lingvistik och Vetenskapsteori, Göteborgs Universitet.

Morten Sager, lektor, Institutionen för Filosofi, Lingvistik och Vetenskapsteori, Göteborgs Universitet.

Carin Staland-Nyman, lektor, Sektionen för Hälsa och Samhälle,Högskolan i Halmstad, samt forskare, Enheten för Socialmedicin, Sahlgrenska akademin vid Göteborgs Universitet.

Gunnel Hensing, professor, Enheten för Socialmedicin, Sahlgrenska akademin vid Göteborgs Universitet livligt under de senaste åren, bland annat de politiska, etiska och sociala aspekterna av att medborgare utförsäkras. Detta fokus har indirekt resulterat $\mathrm{i}$ att mer grundläggande förändringar av sjukskrivningspraktiken och problem med dess tillämpning har hamnat i skuggan. Bedömningar av arbetsförmåga i samband med sjukskrivning är ett problem i läkarens kliniska vardag (Wahlström \& Alexanderson 2004). Inspektionen för socialförsäkringen (IFS) konstaterar att endast $13 \%$ av alla läkarintyg som sänds in till Försäkringskassan håller måttet (Grees, Aili \& Odelmark 2011). Hur kommer sig detta? Är det nonchalans från läkarkå- 
rens sida, tidsbrist eller rentav ett mått av inkompetens? En nyligen avslutad vetenskapsteoretisk studie av det försäkringsmedicinska beslutsstödet indikerar att problemet är av en helt annan art. Den allt starkare betoningen av arbetsförmåga i Försäkringskassans praxis och som grund för utformningen av beslutsstödet synliggör att sjukskrivningsprocessen numera utmanar medicinens normalvetenskapliga gränser. Beslutsstödet grundas på att en sjukdoms konsekvenser för funktionstillstånd och aktivitetsbegränsning ska bedömas i förhållande till patientens arbetsförhållanden [http:// www.socialstyrelsen.se/riktlinjer/forsakringsmedicinsktbeslutsstod]. Denna utgångspunkt i beslutsstödet väcker kunskapsteoretiska frågor om ansvarsoch kompetensområden. Bedömning av arbetsförmåga är en typ av kunskapsobjekt som kräver en breddad expertgemenskap. Bedömningar av arbetsförmåga faller inte inom medicinens normalvetenskapliga ramar utan ska i stället förstås som ett exempel på "post-normal" vetenskap (Funtowicz \& Ravetz 1993; Haag D, Kaupenjohann M 2001; Smith \& Kelly 2003). Post-normala områden utmanar traditionella ämnesgränser och kräver robusta svar där det ännu finns lite evidens eller konsensus. I den här artikeln undersöker vi utvecklingen av det försäkringsmedicinska beslutsstödet och diskuterar det i relation till de vetenskapsteoretiska villkoren för expertis och kunskap omkring "arbetsförmåga". Studien ingår i ett projekt om det försäkringsmedicinska beslutsstödets etablering, implementering och roll i klinisk praxis.

\section{Det försäkringsmedicinska beslutsstödet}

Ett av skälen till att det försäkringsmedicinska beslutsstödet initierades och infördes var att statens kostnader för sjukpenningutbetalningar steg dramatiskt i början av 2000-talet. Sjukskrivningarna blev på ett helt annat sätt än tidigare en politisk fråga. I samband med att sjukskrivningstalen problematiserades noterade man också att statistiken för likartade åkommor varierade radikalt mellan olika geografiska områden. Detta togs som intäkt för att man behövde hitta ett sätt att centralisera och strama upp de kriterier som användes av läkare som grund för att rekommendera sjukskrivning. Inte minst var motivet att minska den regionala variationen i sjukskrivningarnas längd. Ambitionen var att variationer relaterade till den individuella patientens hälsostatus eller arbetssituation skulle utjämnas mellan regionerna.

Det försäkringsmedicinska beslutsstödet publicerades i en första version under hösten 2007 och har sedan dess utvecklats med kontinuerliga tillägg och revideringar. Det består av två delar. En del redovisar de övergripande principer som bör gälla för sjukskrivning. Den andra delen är utformad som en intygsencyklopedi indelad i olika diagnoser enligt en mall som arbetades fram på Socialstyrelsen. Av beslutsstödet framgår hur olika sjukdomar förväntas påverka arbetsförmågan och en rekommenderad sjukskrivningstid anges.

Efter det att beslutsstödet har tagits i bruk finns det åtskilliga praktiska pro- 
blem med dess tillämpning i förhållande till kvaliteten på intyg. När Riksrevisionen granskade sjukintyg från 2007 konstaterade de att bara 1 av 4 intyg innehöll tillräcklig information på intygen för att göra en rättssäker bedömning (RiR 2009:07). Försäkringskassans egen utvärdering kom fram till att knappt hälften, 45 procent, av sjukintygen var av tillräcklig kvalitet (Socialförsäkringsrapport 2011:12). För att råda bot på bristerna i sjukintygen har läkare erbjudits kurser för att bättre möta kraven och finansiella incitament har inrättats för de landsting som kan uppvisa minst 50 procent godkända intyg (Lidwall 2011; Watz Forslund \& Lidwall 2011). Trots dessa insatser fann Inspektionen för socialförsäkringen (IFS) i sin granskning från 2011 att endast en dryg tiondedel av intygen mötte kvalitetskraven (Grees et al.2011).

Syftet med den här artikeln är att fördjupa förståelsen av arbetsförmåga som vetenskapligt kunskapsobjekt och sätta detta i relation till det försäkringsmedicinska beslutsstödets uppbyggnad. Mer specifikt diskuterar vi huruvida den medicinska normalvetenskapliga ansatsen som utgångspunkt bör ersättas med en mer post-normal vetenskaplig ansats för att bedöma arbetsförmåga.

\section{Metodredovisning}

Studien är renodlat kvalitativ och stöder sig på djupintervjuer med sakkunniga som deltagit i processen samt dokumentanalys. Intervjupersonerna har identifierats genom att aktörer som varit centralt placerade och aktiva i framtagningen av beslutsstöden har kontaktats. De har sedan hänvisat vidare till andra personer, som på liknande sätt varit delaktiga i olika delar av processen. Totalt har 15 personer som har varit direkt delaktiga i arbetet djupintervjuats. Intervjupersonerna har valts ut i kraft av sina olika roller i framtagandet av beslutsstödet. Ambitionen har varit att täcka in så många olika perspektiv och stadier i arbetet som möjligt och därför har vi intervjuat högt uppsatta tjänstemän på Socialstyrelsen och Försäkringskassan, deltagare i den s.k. referensgruppen som kommenterade arbetet med de övergripande principerna för beslutsstödet, samt deltagare från de olika expertgrupper som fick i uppdrag av Socialstyrelsen att skriva fram rekommendationer för specifika diagnoser. Utöver detta har vi också intervjuat handläggare och försäkringsmedicinska rådgivare vid Försäkringskassan för att undersöka hur det försäkringsmedicinska beslutsstödet förstås och används vid beslut om sjukskrivning, samt läkare som använder beslutsstödet. Intervjuerna har varat i genomsnitt 1,5 till 2 timmar och har spelats in efter informerat samtycke. Informanterna har själva styrt samtalet i stor utsträckning och beskrivit sitt deltagande i och sina erfarenheter utav arbetsprocessen. Längre fram i intervjuerna har olika teman identifierats och specifikt lyfts fram för diskussion. Intervjumaterialet har transkriberats och systematiserats med hjälp av Atlas Ti, ett specialkonstruerat program för kvalitativ forskningsmetod. Allt material har anonymiserats. Såväl text- som intervjumaterialet har bearbetats genom upprepade genomläsningar och jämförelser. Återkommande teman 
har kodats och annoterats i Atlas Ti och lyfts fram från enskilda intervjuer för att analyseras i en mer sammansatt och renodlad form. De teman som identifierats i intervjumaterialet har sedan länkats till den övergripande dokumentanalysen och utgjort grunden för en kunskapsteoretisk analys. Dokumentanalysen har genomförts genom att relevanta utredningar, PM och rapporter har identifierats. ${ }^{1}$ Vidare har medielandskapet bevakats kontinuerligt med hjälp av Mediearkivet.

\section{Arbetsförmåga i Beslutsstödet}

Begreppet arbetsförmåga som ordnande princip har diskuterats och problematiserats ur en rad olika synvinklar ${ }^{2}$, inte minst från juridiskt håll (Mannelqvist 2012a). Arbetsförmåga är en medicolegal term, d v s själva begreppet härrör sig från en terräng i vilken lagstadgade rättigheter vilar på medicinska grunder. En återkommande reflektion är att begreppet inte definierats av lagstiftaren (Mannelqvist 2008; Järvholm et al. 2009) och att detta gör Försäkringskassans tillämpningar av detsamma starkt normerande (Mannelqvist 2012b; Vahlne Westerhäll 2012). Läkares möjlighet och mandat till

1 Exempel på sådana dokument är propositioner, Statens Offentliga Utredningar, lagtexter (som Prop. 1994/95:147; SFS 1995:508; SOU 1995:149; SOU 2000:121) men också utredningar och uppföljningar från Försäkringskassan samt informationstexter gällande hur läkare bör tänka kring sjukskrivningar.

2 Så t ex har arbetsförmåga behandlats från såväl sociologiskt, statsvetenskapligt, etiskt och medicinskt perspektiv, se Vahlne Westerhäll (2006). att bedöma arbetsförmåga har ifrågasatts (Prop. 2002/03:89) och en rad utbildnings- och informationsåtgärder har föreslagits av lagstiftaren som en lösning på detta problem (Järvsholm et el. 2009). Det försäkringsmedicinska beslutsstödet betraktades som en hjälp för läkare i deras bedömning av arbetsförmåga, samt ett sätt att forma läkarkårens tänkande kring intygsskrivande (Mannelqvist 2008; Eriksson et al. 2014).

Av beslutsstödet framgår det att arbetsförmågebedömningen är en sammanvägning av individens funktionstillstånd, aktivitetsnedsättning och arbetssituation, samt vilka möjligheter det finns att anpassa den senare. Det åligger alltså läkare, både att kunna relatera individens aktivitetsnedsättning till dennes arbetssituation och att bedöma vilka anpassningsmöjligheter som finns av de arbetsförhållanden som råder för olika patienter. I de fall då patienten inte har något arbete skall sjukdomens konsekvenser för arbetsförmågan ställas i relation till "normalt förekommande arbeten på arbetsmarknaden" (Socialstyrelsen 2011a). Senare i en sjukskrivningsprocess är det inte enbart konsekvenserna av funktionstillstånd och aktivitetsbegränsning för arbetssituationen som skall bedömas utan även andra faktorer som kan inverka på återhämtningen av arbetsförmågan. Dessa faktorer är av personlig och kontextuell karaktär, såsom "motivation och personlighet" och "krav och stöd i familjeliv" (ibid.). Det är den behandlande läkaren som antas kunna väga samman dessa olika faktorer även om beslutsstödet också anger att dessa bedömningar kan gagnas av att involvera multiprofessionella team. 
"Arbetsförmåga" som kunskapsobjekt innefattar således en mängd faktorer: diverse arbetssituationers fysiska, kognitiva, emotionella och sociala krav, möjligheterna att anpassa en patients arbetssituation, vilka krav "normalt förekommande arbeten på arbetsmarknaden" kan ställa på en individs funktionstillstånd samt patienters förutsättningar för återhämtning i form av motivation, personlighet och familjesituation. ${ }^{3}$

\section{Experter och expertis vid framtagning av beslutsstödet}

Evidens i form av forskning saknades till stor del för den typ av bedömningar som det försäkringsmedicinska beslutsstödet skulle sammanfatta och generalisera. Det finns ännu inte tillräckligt mycket forskning om arbetsförmåga vid olika sjukdomar för att möjliggöra några tydliga sammanställningar utifrån en stark evidensbas. Som brukligt är i fall där evidens saknas fick man istället förlita sig till expertis och beprövad erfarenhet. Vid framtagningen av beslutsstödet utvidgade man dock inte expertbegreppet, utan rekryterade i princip enkom specialister från olika medicinska områden för att utveckla rekommendationer för de olika diagnosgrupperna.

Arbetet med att ta fram ett beslutsstöd lades således ut på den yrkeskår vars arbetssätt skulle påverkas. Det var

3 För en översikt av hur begreppet arbetsförmåga användes $\mathrm{i}$ den vetenskapliga litteraturen kring den tidpunkt då det försäkringsmedicinska beslutsstödet arbetades fram, se Ludvigsson et al. (2006). läkarkåren, eller snarare ett antal experter och specialister inom kåren, som fick uppdraget att formulera en konsensusuppfattning om lämpliga sjukskrivningsperioder för olika sjukdomstillstånd. Man skulle samtidigt fokusera tydligare på att bedöma nedsättning av arbetsförmåga vid olika sjukdomar. Uppdraget innebar att bidra med medicinsk kunskap till det verktyg som skulle vägleda läkare till att tillhandahålla sådana uppgifter som handläggare på försäkringskassan behöver för att fatta beslut om sjukpenning. Själva formatet eller mallen för beslutsstödet hade dock redan tagits fram av tjänstemän på Socialstyrelsen och begränsade starkt vilka aspekter av sin medicinska expertis de sakkunniga kunde foga till materialet.

Kvalitativa intervjuer med representanter för olika expertgrupper och med tjänstemän från Socialstyrelsen, visar att problem som uppstod och diskuterades under arbetet med att ta fram beslutsstödet på olika sätt återspeglas i sjukskrivande läkares problem med intygsskrivandet - att delar av deras expertkunskap inte får plats i intygsformatet. Citaten nedan illustrerar ett tema som ofta återkom och problematiserades i intervjuerna: Det som tidigare legitimt föll inom ramen för läkarens bedömning - en dialog med patienten över tid, samt tidigare kunskap om dennes förhållanden - passar inte längre in $\mathrm{i}$ bedömningsmallen.

Sakkunnig J: Det står ju ofta då om det avviker frän beslutsunderlaget, sjukskrivningen. Då ska man ju ange det och varför (...) sjukskrivning är ju visserligen grundad på en diagnos och objektiva fynd i utred- 
ningen och status och funktionsbedömning och så men det är ju väldigt mycket utifrån hur den enskilda individen själv upplever sin situation och sin förmåga... så att det är ju väldigt mycket en dialog mellan patient och läkare när man kommer fram till vad somär en rimlig sjukskrivning. ${ }^{4}$

Sakkunnig A: Det är klart, det är en oerhört svår uppgift att... du kan ju tänka dig att... som doktor ser du ju en patient, en person under kanske 20 minuter. Så ska du bedöma hur den personen kan arbeta, i sitt jobb. Och inte bara ja eller nej utan om det är 75 procent, 50 procent eller 25 procent $i$ arbete eller inte. Så att det kräver väldigt mycket erfarenhet och ocksåatt man har en relation med den här patienten som man känner är... om den här patienten säger "nej jag orkar faktiskt inte, jag är helt slut efter att ha varit på jobbet, då bara går jag hem och lägger mig." Om det är så, dåär det förmodligen såatt det här jobbet orkar inte den här personen. Och det kan man inte bedöma när man sitter så här utan det är vad personen säger till en. ${ }^{5}$

Läkare som intervjuades underströk hur viktig förståelse för en patients övergripande situation är för att den medicinska bedömningen av sjukskrivningsbehov ska bli korrekt. I beslutsstödet betonas dock vikten av att sträva mot det man kallar verifierbarhet. Samtidigt som man från Socialstyrelsens sida understryker att bedömningarna ska vara individuella, används begreppet objektivitet som en

4 Läkare J. Intervju, Medlem i expertgruppen. April, 2010.

5 Läkare A. Intervju, Medlem i expertgruppen. Maj, 2010. motvikt. I såväl dokument- som intervjumaterial framgår tydligt att utlåtanden bedöms som undermåliga om de inte understöds av mätningar eller andra typer av test, alternativt formuleras i termer som exakt beskriver de begränsningar som hindrar patienten från att utföra specifika arbetsuppgifter. Läkarens resonemang måste artikuleras, dokumenteras och valideras, helst med hjälp av "objektiva" mätresultat. Ett skäl till att mätresultaten anses vara objektiva är just att de s a s ligger utanför läkarens bedömning; de kan läsas och förstås separat av handläggaren. Man vill i möjligaste mån röra sig bort från subjektiva utlåtanden och därför måste en handläggare kunna följa och validera det underlag eller de undersökningsresultat som läkaren baserat sin bedömning på. Läkares expertkunskap fungerar inte längre som en implicit garant för ett besluts medicinska validitet utan måste externaliseras i form av mätbara resultat (t ex cykel- eller trapptest) eller åtminstone artikulera de konkreta arbetsmässiga konsekvenserna av den medicinskt definierade åkomman, vilket tydliggörs i beslutsstödets övergripande principer:

Det är viktigt att läkaren i varje enskilt patientmöte baserar sina bedömningar på så objektiva kriterier som möjligt, exempelvis $i$ form av validerade skattningsskalor.

Intervjuer med tjänstemän på Socialstyrelsen och Försäkringskassan bekräftade den bild som gavs av läkarna. I dessa samtal tydliggjordes vikten av att "bedömningsfynden" fanns representerade i intyget, $i$ en form som går att förstå separat från 
läkarens övergripande bild av patienten och dennes situation. Läkaren bör inte "fastna" på patientens sjukdom utan koncentrera sig på hur sjukdomen påverkar arbetsförmågan.

Tjänsteman G, Försäkringskassan: Många gånger så återfaller det ju på (...) läkare själva att [man] har faktiskt inte uttryckt [sig] tillräckligt tydligt och framför allt inte när det gäller just dom här försäkringsmedicinska, kritiska uppgifterna, utan (...) har orerat mycket kring hur allvarlig sjukdomen är och vilken behandling som ska ges och hur länge vederbörande har varit sjuk och så, men inte gått in på det här med funktionsnedsättning, aktivitetsbegränsning. ${ }^{6}$

Tjänsteman I, Försäkringskassan: Men du mäter detta då att den här symtomen eller tillstånden ger arbetsoförmåga, det är där vi är (...) Det är ju inte min grej utan det är ju läkaren som gör det för oss. Sedan så gör ju vi bedömning om läkaren gör rätt?

Läkares erfarenhetsbaserade kunskap är dock svår att översätta till ett linjärt synsätt där en sjukdom leder till en funktionsnedsättning som ska dokumenteras "objektivt" och som i sin tur leder till en nedsättning av arbetsförmågan. Den del av sin expertis som läkare använder sig av $i$ en sjukskrivningssituation lånar sig inte till att enkelt översättas från ett kliniskt samtal med en patient till ett dokument som kan användas som underlag för ett

6 Tjänsteman G. Högre tjänsteman, Försäkringskassan. Intervju. Maj, 2010.

7 Tjänsteman I. Handläggare, Försäkringskassan. Intervju. Februari, 2012. beslut gällande arbetsförmåga. En förklaring till en del av de problem man upplevt i gränssnittet mellan läkare och handläggare är att expertis till sin natur är subjektiv. Läkares expertis innefattar en helhetssyn och en förståelse av patientens livsvillkor. I bästa fall har en relation utvecklats till patienten över tid, vilket möjliggjort en nyanserad bedömning av vilka behandlingar som kan antas ge bäst resultat. Denna förmåga att bilda sig en uppfattning om en patients kontext, koppla den till den ställda diagnosen och omsätta helheten $\mathrm{i}$ en behandlingsplan utgör en del av läkares kliniska kunskap, men är svår att förmedla till Försäkringskassan eftersom det inte bedöms vara "försäkringsmedicinskt relevant information". ${ }^{8}$

Själva tanken med beslutsstödet var istället att tillhandahålla en resurs som skulle strukturera tänkandet och praktiken runt läkares intygsskrivande och reglera interaktionen mellan läkare och Försäkringskassan. I citaten nedan lyfts denna aspekt fram av tjänstemän på Socialstyrelsen och Försäkringskassan:

Tjänsteman F, Socialstyrelsen: Hela stödet kan man säga bygger på den här samtidigheten. En av de saker som är unikt med det här är att det riktar sig samtidigt [till läkare och handläggare]. Och det ger en effektfullhet till det här som skulle varit svår att nà annars. Alltså att det finns en aktör som använder det här $i$ sin dialog med en annan aktör, det som tvingar fram ett användande såatt säga.

8 Tjänsteman G. Högre tjänsteman, Försäkringskassan. Intervju. Maj, 2010. 
Tjänsteman F, Socialstyrelsen: Hur man ska skriva de här avstegen är förstås inte lätt, det är en evolution på gång där. Läkarkåren lär sig detta och blir bättre på det, samtidigt som Försäkringskassan skruvar upp sina anspråk och sin ambitionsnivå, så på det viset driver de här systemen varandra.

Tjänsteman G, Försäkringskassan: Kan bara doktorn, om doktorn förstår det, det mer medicinska sammanhanget, det vill säga, vad som faktiskt ska beskrivas och förmedlas till försäkringen, då har ju doktorn fortfarande makten (...) Men all den stund doktorn inte har förstått det, utan fortsätter med halvkväden eller ofullständig information eller information som inte är av försäkringsmedicinsk stringens, då har man ju förflyttat makten, för att då har man ju då hjälpmedel $i$ form av beslutsstöd och man har, eh, ja kanske andra kunskapskällor också som man då kan hänvisa till för att gå emot doktorns önskemål om sjukskrivning.

Beslutsstödet har fungerat som ett sätt att styra och avgränsa kommunikationen av information och kunskap mellan läkare och myndighet. Läkares expertis innefattar en övergripande bild och insikt i patientens livsvillkor. Det är dock inte denna situerade expertkunskap som efterfrågas av Försäkringskassan; i synnerhet inte representerat i den form som tidigare har varit vanligt i sjukintyg.

\section{Experter och legitimitet}

Som nämnts ovan är expertrollen extra viktig i ett fält där en gedigen evidensbas ännu saknas; i brist på en samlad och strukturerad kunskapsanalys förlitar man sig istället på beprövad erfarenhet. Att sakna evidens är inte i sig en unik situation vid skapande av vägledande råd för klinisk praktik. I viktiga avseenden har det försäkringsmedicinska beslutsstödet tagits fram under samma betingelser som andra riktlinjeprojekt inom Socialstyrelsen med eller utan evidens. Även inom evidensrika områden som kardiologi finns det fall där det saknas forskning (i vissa fall kan forskning överhuvudtaget inte bedrivas). I fall där det saknas forskning får expertgrupper en stor betydelse för tolkningen av kunskapsläget (Bohlin \& Sager 2011). I fallet med framtagandet av beslutsstödet blev nästan uteslutande läkare anlitade som experter $\mathrm{i}$ arbetet med ta fram rekommendationer gällande hur arbetsförmåga kunde påverkas av olika sjukdomstillstånd. Utan trovärdighet blir riktlinjerna inte tillämpade och enligt tjänstemän på Socialstyrelsen som arbetade med att ta fram beslutsstödet var detta inledningsvis ett bekymmer. I en klinisk situation som tidigare inte reglerats nämnvärt från centralt håll utgjorde beslutsstödet en utmaning mot läkares självbestämmande. Det kom tydliga signaler initialt att stora delar av läkarkåren var negativt inställd. Dock lyckades Socialstyrelsens enligt egen utsago att med tiden skapa en relativt hög trovärdighet för beslutsstödet och en av strategierna man använde var att identifiera nyckelpersoner och organisationer hos vilka man kunde förvänta sig intresse för den övergripande tanken med projektet. Inledningsvis arbetade man med aktörer som hade ett särskilt intresse för sjukskriv-

Eriksson, Sager, Staland-Nyman \& Hensing: Expertis, sjukskrivning och mötet... 
ningsfrågor och lät dem kontinuerligt komma med synpunkter på den modell som i huvudsak togs fram av den projektansvarige tjänstemannen på Socialstyrelsen.

Tjänsteman A, Socialstyrelsen: Jo men det var jätteintressant, men det var lite nervöst $i$ och med att de hade förstått att det här inte sågs helt med blida ögon bland läkarprofessionen, det hade varit ganska tufft [...] Men redan från början hade vi fätt höra och fätt känslan av att det här kommer vi få motarbete för, mothugg. Och i början var det väldigt mycket. Jag vet när [namn] tog kontakt med alla de här specialitetsföreningarna och läkarprofessionen för att få personer som ville jobba med det här så var det svårt $i$ början. "Det här kommer ju inte funka! Det här kan ni inte komma med någonting från Socialstyrelsen och säga hur vi läkare ska arbeta. Det kommer inte gå att få några generella rekommendationer för det är så individuellt, och det här vet ju läkarna!" och så där. Men sedan ju mer vi jobbade med det här, jag vet att [namn] hade redan där gjort ett ganska bra arbete $i$ och med att han trots all hade fätt kontakt med mycket läkare och då hittade man några som var positiva och kände att det här behövs det ju verkligen stöd för, sjukskrivning är ju så jäkla jobbigt och tråkigt att sitta med, så det är bra att det kommer stöd. Så vi hade fått några positiva eldsjälar som var med. Och det där spred sig lite allt eftersom via läkarna som var med och via specialitetsföreningarna som var engagerade och så. ${ }^{9}$

9 Tjänsteman A. Intervju. Socialstyrelsen. Maj. 2010.
Legitimitet har varit en angelägen fråga i framarbetandet av Beslutsstödet och behovet av trovärdighet har med viss självklarhet krävt läkares medverkan. Parametrarna för deras medverkan har satts så att delar av deras sakkunskap fallit utanför ramarna för uppgiften. Andra yrkesgrupper har inte i nämnvärd utsträckning anlitats som sakkunniga i processen med att ta fram specifika rekommendationer. Det begrepp som legat till grund för hela modellen - arbetsförmåga - tycks ha förblivit förhållandevis oproblematiserat i den bemärkelse att man inte försökt identifiera vem eller vilka grupper utöver läkarkåren som skulle kunna sägas ha expertkunskap på detta område.

\section{Diskussion - Normalvetenskap och post- normal kunskap}

Det finns en grundläggande kunskapsteoretisk tvetydighet i beslutsstödet, då det bygger på läkares kliniska expertis och praktik, samtidigt som det vill förändra denna praktik. Något tillspetsat kan man konstatera att det i viss mån är beslutsstödets strikt diagnosbaserade struktur som skapar en diskrepans mellan den logik sjukintygsblanketten tillhandahåller och den faktiska situation i vilken läkare använder sin sjukskrivningsexpertis. Betoningen på diagnos i verktygets uppbyggnad, samtidigt som man kraftfullt avfärdar enbart sjukdom som ett giltigt skäl till sjukskrivning utgör en paradox.

Begreppet arbetsförmåga faller inte inom den traditionellt definierade ramen 
för medicin och ställer nya krav på läkares expertis. Beslutsstödet riktar sig till en läkarprofession som besitter en expertis som är relevant men inte heltäckande. En sådan expertis i arbetsförmågebedömningar kan inte skapas eller utvecklas genom ett beslutsstöd. När nationella riktlinjer används kliniskt ansluter de alltid till en existerande och i grunden fungerande praxis för att kvalitetssäkra eller likrikta denna. Nationella riktlinjer antas inte kunna skapa en ny kompetens om nya kunskapsobjekt. Vetenskaplig kunskap bildas inom ett paradigm där metoder, kriterier och kompetenser är tydligt definierade och accepterade (Kuhn, 1962). När ett paradigm är etablerat bedrivs vad som i den traditionella vetenskapsteorin kallas "normalvetenskap". Ibland väcks frågeställningar som inte enkelt lånar sig till att förstås inom ramen för ett givet paradigm, inte minst vid samhällelig hantering av riskabel teknologi då stor osäkerhet råder och mycket står på spel för många aktörer. Ursprungligen utvecklades begreppet post-normal vetenskap för att beskriva och metodologiskt hantera en ny typ av problem som vetenskapssamhället ställs inför som en följd av samhällets förändring. Post-normal vetenskap hanterar problem som berör olika intressenter vilka påverkas av beslut som måste fattas snabbt och vara robusta, trots den höga grad av osäkerhet (uncertainty) som omger problemet. I många fall är frågan om vem som har relevant expertis svår att besvara då dessa dilemman inte begränsar sig till traditionellt definierade disciplinära ramar. Sådana "post-normala" kunskapsobjekt kräver en vidgad förståelse och användning av exper- tis, s.k. extended peer communities eller breddad expertgemenskap (Funtowicz \& Ravetz 1993; Turnpenny, Jones \& Lorenzoni 2011). Det finns ingen given expert för post-normal kunskap utan flera typer av expertis behöver kombineras för att kunna skapa vägledning för allmänhet och beslutsfattande. Post-normal vetenskap är kontextdriven och inbegriper ett flertal perspektiv, till skillnad från normalvetenskap där problemen både definieras och löses inom en given akademisk disciplin.

Begreppet "arbetsförmåga" är i denna mening inte normalvetenskapligt utan post-normalt. Eftersom arbetsförmåga ännu är ett post-normalt kunskapsobjekt kan inte ett beslutsstöd skapa den expertis som läkarkåren enligt egen utsago delvis saknar. För att skapa sådan expertis krävs helt andra typer av insatser.

Hos Socialstyrelsen finns en uttalad ambition att gradvis träna läkare till att skriva intygen på rätt sätt. Tanken med beslutsstödet är att tillhandahålla en informationsresurs som också kommer att fungera som en grammatik som strukturerar tänkandet och praktiken runt intygsskrivande. Ur en vetenskapsteoretisk synvinkel finns det dock en risk att ett ökande antal godkända läkarintyg inte skulle vara ett tecken på att beslutsstödet underlättat arbetsförmågebedömningarna, utan på att läkare lärt sig att 'skriva rätt'. Det som nu mäts av flera myndigheter och som genom utbildningsinsatser och stimulansåtgärder skall förstärka är kvaliteten på sjukintyget. Medan det är möjligt att en sådan kvalitetsförbättring av sjukintygen också är en kvalitetsförbättring av arbetsförmågebedömningarna, är det inte nödvändigtvis 
så. Kvaliteten på sjukintygen är i bästa fall ett substitutmått på den faktiska kvaliteten i bedömningar av arbetsförmåga. För att uppnå ökad kvalitet i arbetsförmågebedömningar krävs att detta post-normala kunskapsobjekt tas på allvar och integreras i forskning och utbildning i likhet med andra objekt man eftersträvar expertis för.

Det försäkringsmedicinska beslutsstödet tydliggör en förskjutning av den sjukskrivande läkarens uppgift till att, utöver att diagnosticera en sjukdom och dess inverkan på patientens funktioner, också bedöma dess konsekvenser på förmågan att arbeta (Vahlne Westerhäll, Thorpenberg \& Jonasson 2009). Att arbetsförmåga är ett i praktiken svårgripbart begrepp som inte oproblematiskt faller inom någon professions kognitiva jurisdiktion ${ }^{10}$ har tidigare uppmärksammats från ett flertal håll, inte minst från lagstiftaren själv (Prop. 1994/95:147; Mannelqvist et al. 2010; Mannelqvist 2012a,b). Läkares erfarenheter av otillräcklighet vid sjukskrivning är ett följdriktigt uttryck för två separata men relaterade problem: att formatet för beslutsstödet begränsar vilka aspekter av sin expertkunskap läkare kan förmedla till Försäkringskassan, samt att man tvingas hantera ett post-normalt kunskapsobjekt utanför sin etablerade expertis. Med nuvarande frågeställningar och strategier åtgärdas symtomen på ett kunskapsteoretiskt glapp, snarare än att i grunden höja expertisen kring arbetsförmåga.

Expertis växer fram i expertgemenskaper genom delad begreppsbildning och

10 För en utförlig diskussion av kognitiv auktoritet och professionalism, se Freidson (1986, 2001). gemensamma praktiker (Collins 2010). Det krävs också en mödosamt upptränad kompetens, ett handlag, för att in situ kunna göra korrekta bedömningar; detta är exempelvis skälet till de avsevärda kliniska momenten i läkarprogrammet, samt till AT-tjänstgöring och ST-block där erfarna läkare handleder yngre kollegor.

Med arbetsförmågan i centrum för sjukförsäkringen bör en sådan expertis också stå i centrum för ansträngningarna. Man har hittills förlitat sig på expertis grundad i samma praktik som man vill förändra. Utveckling av expertis kräver dock mer djupgående processer. Data från både FK och ISF påvisar brister i sjukintygen och vissa myndigheter efterfrågar djupare analyser snarare än fler stimulansåtgärder riktade till läkare (Grees et al. 2011; Lidwall 2011; Watz Forslund \& Lidwall 2011). Vår nyligen avslutade studie visar att de problem som nu påtalas inte härrör från bristande kompetens eller engagemang från sjukskrivande läkare utan snarare från uppgiftens postnormala karaktär, vilken går bortom läkares normalvetenskapliga expertis. Tidigare studier bland läkare har identifierat bedömning av arbetsförmåga som ett dilemma och att bristande förmåga att arbeta inte på något självklart sätt låter sig beskrivas genom en medicinsk diagnos (Timpka, Hensing \& Alexanderson 1995). Det omvända har också beskrivits. En medicinsk diagnos reflekterar oftast inte en viss arbetsförmåga.

Vetenskapsteoretisk forskning om expertkunskap gör tydligt att expertis är förmågan att göra initierade bedömningar grundade på erfarenhet, det som ofta 
kallas 'tyst kunskap' (Collins 2010; Collins \& Evans 2002; Wynne 1989; Wynne 1992; Coopmans \& Button 2014). För att handläggarna ska kunna fatta ett beslut måste dock läkarnas expertbedömningar göras tillgängliga och externa. Ett möjligt sätt att förstå saken är att den reella sjukskrivningsexpertisen nu på ett tydligare sätt har flyttats från läkarkåren till Försäkringskassans handläggare. Om det är så kan läkares roll i sjukskrivningsärenden utvecklas mot att fungera mer som en serviceenhet som tillhandahåller underlag för bedömningar av arbetsförmåga snarare än att göra bedömningen. Den nya arbetsförmågeutredningen (AFU) som nu är under utveckling inom Försäkringskassan tyder eventuellt på detta. AFU ska användas av handläggare för att hjälpa dem att fatta beslut, och innefattar beskrivningar av olika typer av arbeten, vilka uppgifter de tenderar att inbegripa och de belastningar som dessa kan innebära. Vid AFU kommer man att begära medicinsk och funktionsbedömning utförd av läkare med särskild utbildning som ett underlag i bedömningen. ${ }^{11}$

11 AFU har varit föremål för livlig diskussion, en vanlig kritik som framförts har varit att dessa utredningar fördjupar den försäkringsmedicinska problematik som Beslutsstödet redan är ett exempel på, nämligen att man utgår från normerande schabloner på gruppnivå för att göra bedömningar för en försäkring som är individuell och kräver individuellt anpassade beslut. I denna artikel behandlar vi dock inte denna problematik, utan hänvisar till AFU endast som ett illustrerande exempel som visar att läkarkårens roll visavi Försäkringskassan och sjukskrivningar är stadd i politisk och praktisk förändring.
Det förekommer post-normala kunskapsområden inom vård och omsorg som hanteras genom breddade expertsammansättningar, multiprofessionellt och tvärdisciplinärt, ofta i form av team med flera kompetenser än enbart medicin. Socialstyrelsens riktlinjer om rörelseorganens sjukdomar är ett aktuellt sådant exempel, men inom exempelvis psykiatrisk vård är sådana samarbeten legio. En breddad expertsammansättning skulle kunna inbegripa sjukgymnaster, arbetsterapeuter, kuratorer, försäkringsmedicinska experter och försäkringshandläggare vars expertis handlar om relationen mellan fysiska begränsningar och arbetsuppgifter.

Oavsett vilken yrkesgrupp som i slutändan gör bedömningarna så rekommenderar vi att eventuella verktyg som tas fram beaktar arbetsförmågebegreppets postnormala karaktär. En sådan uppgift kräver i förstone en bred expertgemenskap, men framförallt en förståelse för hur ny expertis arbetas fram. Det är en grannlaga och långsiktig process för berörda myndigheter, institutioner, professioner och vetenskapliga discipliner som sträcker sig bortom en eller två mandatperioder. 


\section{Referenser}

Bohlin, I. \& Sager, M. (eds.) (2011). Evidensens många ansikten: evidensbaserad praktik i praktiken. Lund:Arkiv Förlag.

Collins, HM. (2010). Tacit and Explicit Knowledge. Chicago: University of Chicago Press.

Collins, HM. \& Evans, R. (2002). The third wave of science studies studies of expertise and experience. Social studies of science. 32(2): 235-296.

Coopmans, C. \& Button, G. (2014). Eyeballing expertise. Social Studies of Science. 44(5): 758785.

Eriksson, L., Sager, M., Staland-Nyman, C., Hensing, G. (2014). Kunskap och bedömningar i sjukskrivning: en vetenskapsteoretisk studie av det försäkringsmedicinska beslutsstödet. Socialmedicinsk tidskrift (3): 42-48

Freidson, E. (1986). Professional powers. Chicago: University of Chicago Press.

Freidson, E. (2001). Professionalism - the third logic. Cambridge: Polity Press.

Funtowicz, SO. \& Ravetz, JR. (1993). Science for the Post-Normal Age. Futures. 25(7): 739-55.

Grees, N., Aili K. \& Odelmark J. (2011). Försäkringskassans hantering av underlag för beslut om sjukpenning. Rapport 2011:8. Stockholm: Inspektionen för Socialförsäkringen (ISF).

Haag, D. \& Kaupenjohann, M. (2001). Parameters, prediction, post-normal science and the precautionary principle - a roadmap for modelling for decision-making. Ecological Modelling. 144(1): 45-60.

Järvholm, B., Karlsson, B. \& Mannelqvist, R. Arbetsförmåga i sjukförsäkringen - så beskrivs begreppet i lagstiftningen. Läkartidningen. 106:1178-81.

Kuhn, TS. (1970/1962). The Structure of Scientific Revolutions. Chicago: Chicago University Press.

Lidwall, U. (2011). Försäkringsmedicinska beslutsstödet. En långtidsuppfölining av förändringar $i$ sjukskrivningsmönster. Socialförsäkringsrap- port 2011:7. Stockholm: Försäkringskassan.

Ludvigsson, L., Svensson, T. \& Alexandersson, K. (2006). Begreppet arbetsförmåga - en litteraturgenomgång. Ort:Arbetslivsinstitutet.

Mannelqvist, R. (2008). Arbetsförmåga i sjukförsäkringen - lagstiftarens motiv. Förvaltningsrättslig tidskrift. (4):509-33.

Mannelqvist, R. (2012). Möten mellan juridik och medicin i sjukförsäkringen. Förvaltningsrättslig tidskrift.(2):186-99.

Mannelqvist, R. (2012). Arbetsförmåga i sjukförsäkringen: rätt och tillämpning. Uppsala: Iustus förlag.

Mannelqvist, R., Karlsson, B. \& Järvholm, B. (2010). Läkarintyg om bedömning av arbetsförmåga klarar inte alltid rättslig prövning. Läkartidningen. 49:3125-3127.

Prop. 1994/95:147 Rätten till förtidspension och sjukpenning samt folkpension för gifta.

Prop. 2002/03:89 Förändringar inom sjukförsäkringen för ökad hälsa $i$ arbetslivet.

Riksrevisionen (2009). Beslut om sjukpenning har Försäkringskassan tillräckliga underlag? Stockholm; RiR 2009:03.

Smith, W. \& Kelly, S. (2003). Science, technical expertise and the human environment. Progress in Planning. 60: 321-394.

Socialförsäkringsrapport (2011:12). Kvalitetsgranskning av läkarintyg. En del av sjukskrivningsmiljarden. Försäkringskassan, Analys och Prognos.

Socialstyrelsen (2011a). Försäkringsmedicinskt beslutsstöd: Övergripande principer för sjukskrivning. [cited 2011-06-24]; Available from: http://www.socialstyrelsen.se/riktlinjer/forsakringsmedicinsktbeslutsstod/overgripandeprinciperforsjukskrivning

Socialstyrelsen (2011b). Försäkringsmedicinskt beslutsstöd. 2011 [cited 2011-06-24]; Available from: http://www.socialstyrelsen.se/riktlinjer/forsakringsmedicinsktbeslutsstod

Statens Offentliga Utredningar (1996). För- 
säkringsskydd vid Sjukdom. SOU 1995:149.

Stockholm: Socialdepartementet.

Svensk författningssamling. Lag (1995:508) om ändring i lagen (1962:381) om allmän försäkring.

Timpka, T., Hensing, G. \& Alexanderson, K. (1995). Dilemmas in sickness certification among Swedish physicians. European Journal of Public Health. 5(3): 215-9.

Turnpenny, J., Jones, M \& Lorenzoni, I. (2011). Where Now for Post-Normal Science?: A Critical Review of its Development, Definitions, and Uses. Science Technology and Human Values. 36(3): 287-306.

Vahlne Westerhäll, L., Thorpenberg, S., Jonasson, M. (eds.) (2009). Läkarintyget i sjukskrivningsprocessen Styrning, legitimitet och bevisning. Stockholm: Santérus.

Vahlne Westerhäll, L. (red.) (2008). Arbets(o) förmåga - ur ett mångdisciplinärt perspektiv.
Stockholm: Santérus förlag.

Vahlne Westerhäll, L. (2012). Rättsstatliga aspekter på sjukförsäkrings-processen med betoning på begreppen sjukdom och arbetsoförmåga. Förvaltningsrättslig tidskrift. (2):201-26.

Wahlström, R. \& Alexanderson, K. (2004) Chapter 11. Physicians' sick-listing practices. Scand J Public Health Suppl. 63: 222-55.

Watz Forslund, I. \& Lidwall, U. (2011). Försäkringsmedicinskt beslutsstöd. En rapport om användandet, motiveringar till överskriden tid samt förändringar $i$ sjukskrivningsmönster. Stockholm: Försäkringskassan.

Wynne, B. (1989). Sheepfarming after Chernobyl: A case study in communicating scientific information. Environment: Science and Policy for Sustainable Development. 31(2):10-39.

Wynne, B. (1992). Misunderstood misunderstanding: Social identities and public uptake of science. Public understanding of science. 1(3):281-304.

Eriksson, Sager, Staland-Nyman \& Hensing: Expertis, sjukskrivning och mötet... 


\section{Summary}

\section{Expertise, sick-leave and the meeting between normal and post-normal science}

Doctors are finding it difficult to issue sick-leave certificates that will meet the requirements of the Swedish Social Insurance Agency. The qualitative study at hand has examined the construction of a new medical decision-making tool introduced into the Swedish health care system to ensure more uniform assessment of sick leave. The tool aimed to guide practitioners when they provide certificates used as grounds for granting sick leave. It was developed under a tight schedule with strict templates for its format that circumscribed the input from enlisted medical experts. Rather than structuring doctors' clinical expertise, the decision-making tool in its current format renders part of that expertise obsolete. A central aim in the process was to produce standardized medical assessments of how a particular illness was expected to affect patients' capacity to work, rather than how the illness affected the patient. The evidential basis for such assessments is scant. Conditions that were not somatic or could not be "measured objectively" proved extra problematic, as much of the assessment then hinges on doctors' experience-based expertise combined with their understanding of the circumstances of individual patients. Our analysis shows that "work capacity" does not fall squarely within the remit of medical expertise, but is an example of "post-normal science" that requires a broad range of experts from different fields to come together to pool their knowledge and build new expertise. We raise the issue of whether an increased emphasis on work capacity may represent a gradual shift of cognitive jurisdiction and responsibility from doctors to social insurance officers. 